\title{
A Single Amino Acid Substitution in the Renal Betaine/GABA Transporter Prevents Trafficking to the Plasma Membrane
}

\author{
Christopher R. Day, Sashana S. Gordon, Cherissa L. Vaughn, and Stephen A. Kempson \\ Department of Cellular and Integrative Physiology, Indiana University School of Medicine, Medical Science Building 385, \\ 635 Barnhill Drive, Indianapolis, IN 46202-5120, USA
}

Correspondence should be addressed to Stephen A. Kempson; skempson@iupui.edu

Received 29 November 2012; Revised 22 March 2013; Accepted 29 March 2013

Academic Editor: Andre Van Wijnen

Copyright (C) 2013 Christopher R. Day et al. This is an open access article distributed under the Creative Commons Attribution License, which permits unrestricted use, distribution, and reproduction in any medium, provided the original work is properly cited.

\begin{abstract}
One response to hypertonic stress in the renal medulla and MDCK cells is the upregulation of betaine transporter (BGT1) synthesis, followed by trafficking to the plasma membrane (PM) and an increase in betaine transport. Upregulation of BGT1 was enhanced by inhibitors of phosphatases PP1 and PP2A and was attenuated by inhibitors of protein kinase C, suggesting an important role for phosphorylation reactions. This was tested using mutants of BGT1 tagged with EGFP. The PM trafficking motifs of BGT1 reside near the $\mathrm{C}$ terminus, and truncation at lysine ${ }^{560}$ resulted in a protein that remained intracellular during hypertonic stress. This K560 $\Delta$ mutant colocalized with endoplasmic reticulum (ER). Substitution of alanine at $\mathrm{Thr}^{40}$, a putative phosphorylation site, also prevented trafficking to the PM during hypertonic stress. Live-cell imaging showed that T40A was not retained in the ER and colocalized with markers for Golgi and endosomes. In contrast, substitution of aspartate or glutamate at $\mathrm{Thr}^{40}$, to mimic phosphorylation, restored normal trafficking to the PM. HEK293 cells transfected with K560 $\Delta$ or T40A mutants had $10 \%$ of the GABA transport activity of native BGT1, but normal transport activity was restored in cells expressing T40E. Normal BGT1 trafficking likely requires phosphorylation at $\mathrm{Thr}^{40}$ in addition to C-terminal motifs.
\end{abstract}

\section{Introduction}

The hypertonicity of interstitial fluid in the renal medulla, more than $1,000 \mathrm{mosmol} / \mathrm{kg}$ in humans, is essential for excretion of concentrated urine and for conserving water for the body. Mammalian cells in a hypertonic environment will lose water rapidly and shrink which, if prolonged, leads to misfolding and aggregation of proteins, cell cycle delay, apoptosis, and necrosis [1-3]. One cellular defense against hypertonicity is intracellular accumulation of organic compounds termed osmolytes which do not interfere with normal cell functions. As the intracellular osmolyte concentrations increase, the cell volume also increases due to osmotic entry of water, and the intracellular ionic strength is reduced. The process is slow, up to $24 \mathrm{~h}$, because gene expression is involved. In renal medullary cells, which are chronically exposed to hypertonic stress, both plasma membrane transporters for osmolytes (e.g. betaine, myo-inositol, and taurine) and intracellular enzymes for synthesis of other osmolytes (principally sorbitol and glycerophosphorylcholine) are transcribed and synthesized. Upregulation of a heat shock protein (HSP70) helps to protect cells from the damaging effects of high concentrations of urea [4]. These processes are driven by a transcription factor (termed TonEBP or NFAT5) that accumulates in the nucleus during onset of hypertonic stress [5-8]. Activation of transcription is likely due to signaling by multiple kinase pathways [9-12].

Little is known about the protein trafficking steps that are required for insertion of newly synthesized osmolyte transporters in the plasma membrane of renal medullary cells. Control of this process may be another critical step in upregulation of osmolyte accumulation during hypertonic 
stress [13]. Phosphorylation steps appear to be required for successful targeting of some plasma membrane transport systems such as aquaporin-2 [14], anion exchanger 1 [15], a urea transporter [16], and NKCC [17] in kidney cells during hypertonic stress. This study is focused on hypertonic upregulation and trafficking of the renal betaine/GABA transporter (BGT1). The primary role of BGT1 in the kidney is to transport the osmolyte betaine, but it can also accept GABA as a substrate [18], and GABA has been used extensively in this laboratory to monitor the transport activity of BGT1 $[19,20]$. The primary structure of BGT1 contains potential phosphorylation sites on intracellular loops [21], and there is some evidence for regulation in situ by protein kinase C [22, 23]. Our goal was to determine the potential importance of phosphorylation in the initial upregulation of BGT1 transport activity during adaptation to hypertonic stress.

\section{Methods}

Cell lines were purchased from American Type Culture Collection, Rockville, MD, USA. Madin Darby canine kidney (MDCK, \#CCL-34) cells were used between passages 15 and 40 and were grown in a 1:1 mixture of DMEMHam's F12 containing $10 \%$ bovine calf serum penicillin $(100 \mathrm{IU} / \mathrm{mL})$ and streptomycin $(100 \mu \mathrm{g} / \mathrm{mL})$. Cultures were maintained in an atmosphere of $5 \% \mathrm{CO}_{2}$ in air. The same medium was used for growth of human embryonic kidney (HEK293, \#CRL-1573) cells. Cells were grown on coverglasses for microscopy and in plastic 24-well plates for transport studies. The transport activities of BGT1, amino acid transport system A (ATA2), and taurine (TauT) in MDCK cells were measured as $\mathrm{Na}^{+}$-dependent uptakes of $\left[{ }^{3} \mathrm{H}\right] \mathrm{GABA}$, $\left[{ }^{14} \mathrm{C}\right]$ methylaminoisobutyric acid, and $\left[{ }^{3} \mathrm{H}\right]$ taurine, respectively, by whole cells as described previously $[19,20,24,25]$.

BGT1 tagged at the $\mathrm{N}$ terminus with enhanced green fluorescent protein (EGFP, Clontech) was previously shown to behave and function identically to native BGT1 when expressed in MDCK cells $[19,26]$. Using the Prosite database (ExPASy Proteomics Server, Swiss Institute of Bioinformatics), four potential phosphorylation sites for PKC were identified on cytoplasmic regions of BGT1. These sites (T40, T235, S418, and S564) were highly conserved in rat, mouse, human, and dog BGT1, based on multiple sequence alignments. Single mutations were created at each site by substituting the neutral amino acid alanine (A) in EGFPBGT1. Additional substitutions at T40 were made with glutamate (E) or aspartate (D) to add a charged group to mimic phosphorylation at this site [27]. Lastly, native EGFPBGT1 was terminated at K560 by introducing a stop codon to produce a mutant $(\mathrm{K} 560 \Delta)$, which lacked the basolateral plasma membrane targeting motifs near the $\mathrm{C}$ terminus of BGT1, namely, the 8 residues in positions 565-572 [28]. The same sequence is needed also for exit from the endoplasmic reticulum [28], so the $\mathrm{K} 560 \Delta$ mutant will be expected to colocalize with a marker for this organelle, as a positive control. Mutations were performed by using the QuikChange site-directed mutagenesis kit (Stratagene, La Jolla, CA, USA) in the laboratories of Dr. G. Burckhardt (University of Gottingen, Germany) and Dr. S. Rhodes (Indiana University
School of Medicine, IN, USA) and were confirmed by DNA sequencing.

After plating on $25 \mathrm{~mm}$ coverglasses for $24 \mathrm{~h}$, subconfluent MDCK cells were cotransfected with EGFP-BGT1 (or mutant) and one of several organelle markers each tagged with mCherry (red fluorescence, Clontech). The endoplasmic reticulum marker was calnexin, and the Golgi marker was the N-terminal 45 amino acids (135 nucleotides) of human sialyltransferase (SiT). The endosomal marker was RhoBGTPase from Clontech. All were tagged with mCherry in the laboratory of Dr. M. Davidson (Florida State University, Tallahassee, FL, USA). The GeneJammer transfection reagent was used according to the protocol provided by the manufacturer (Stratagene), and cells were returned to the $\mathrm{CO}_{2}$ incubator for $24 \mathrm{~h}$ before further use. Following transfection, the coverglasses were placed in growth medium lacking phenol red to minimize background fluorescence and made hypertonic $(500 \mathrm{mOsm})$ by $\mathrm{NaCl}$ addition for $4 \mathrm{~h}$. The coverglasses were processed in the same medium for live-cell epifluorescence imaging using an ISS ALBA workstation (ISS Inc. Champaign, IL, USA) equipped with an Olympus IX71 inverted microscope. EGFP was imaged with excitation at 488 $\mathrm{nm}$ and emission at 500-550 nm. Excitation and emission for mCherry were $587 \mathrm{~nm}$ and $610 \mathrm{~nm}$, respectively.

In a separate study, some batches of MDCK cells grown on coverglasses were transfected with either native EGFPBGT1 or the T40A mutant and were subjected to hypertonic stress $(500 \mathrm{mOsm})$. After $5 \mathrm{~h}$, the cells were prepared for immunohistochemistry and confocal microscopy by fixation in $4 \%$ paraformaldehyde, permeabilized in $0.2 \%$ Triton X100 , and incubated for $60 \mathrm{~min}$ with primary antibodies to furin (Santa Cruz Biotechnology, 1:100 dilution,), an endoprotease used as a marker for the trans-Golgi network [29]. This was followed by $30 \mathrm{~min}$ incubation with goat anti-rabbit IgG conjugated to Cy5 (1:200 dilution, Jackson ImmunoResearch, West Grove, PA, USA). Excitation and emission for Cy5 were 650 and $670 \mathrm{~nm}$, respectively.

Delivery of EGFP-BGT1 or mutants to the plasma membrane was assessed by two methods. First, by expression in HEK293 cells which lack endogenous BGT1. After transfection overnight, the cells were checked for transfection efficiency by visual inspection of fluorescence, followed by incubation in hypertonic $(450 \mathrm{mOsm})$ growth medium for $6 \mathrm{hr}$ to induce trafficking of the expressed protein to the plasma membrane [19]. A $6 \mathrm{~h}$ exposure to osmolality of $450 \mathrm{mOsm}$ was chosen, because HEK293 cells proved to be less tolerant of hypertonic stress than MDCK cells. Plasma membrane localization of the expressed transport protein was determined indirectly based on measurement of $\mathrm{Na}^{+}$-dependent $\left[{ }^{3} \mathrm{H}\right] \mathrm{GABA}$ uptake by whole cells. Second, the same mutants were expressed in MDCK cells for direct visualization of subcellular distribution by confocal microscopy following overnight hypertonic stress (500 mOsm) and paraformaldehyde fixation.

Transport data are expressed as the mean \pm SD of at least three separate experiments, and within each transport experiment the mean value $(n=1)$ was derived from triplicate measurements. Where appropriate, different groups 

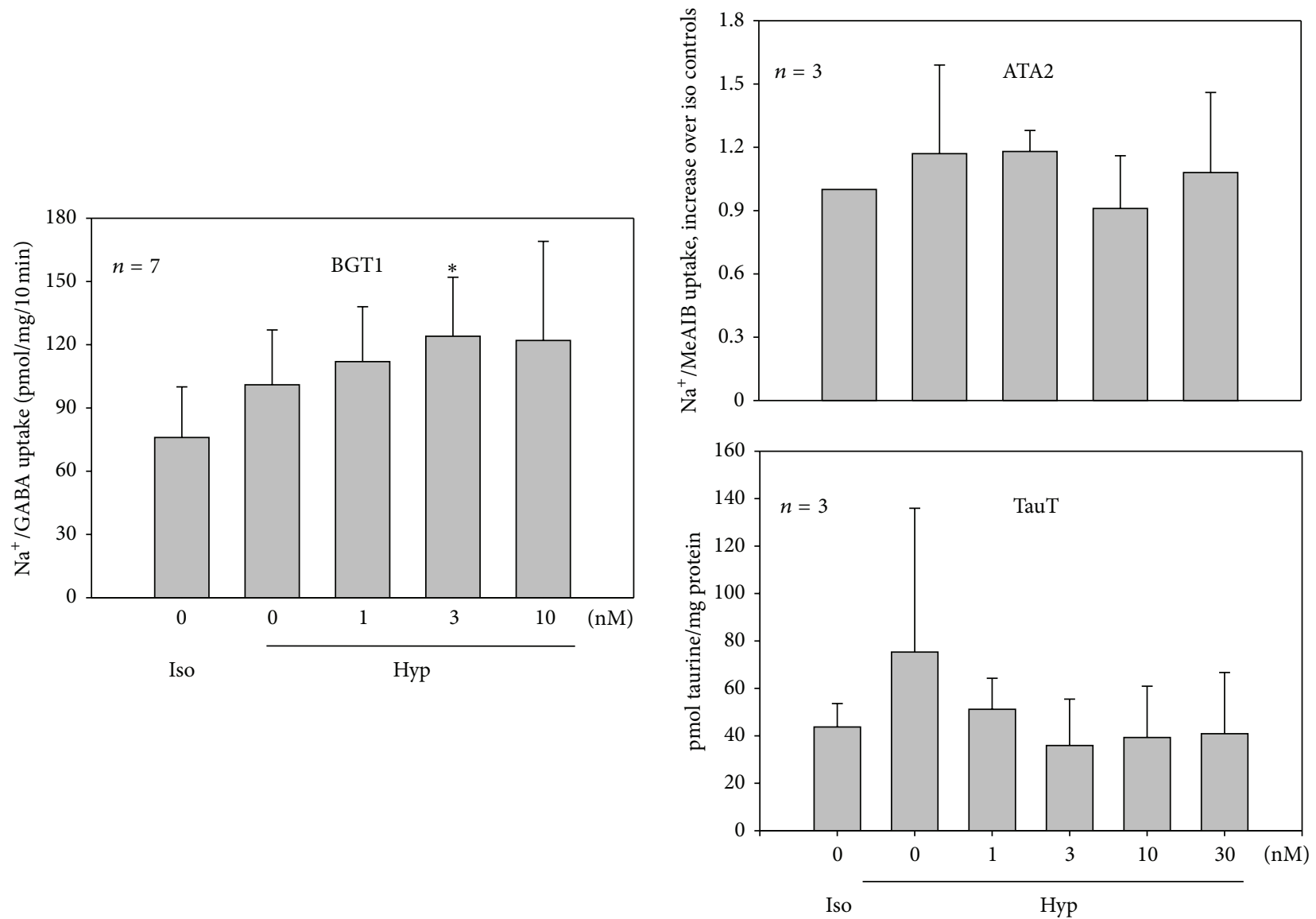

FIgURE 1: Incubation of MDCK cells for $3 \mathrm{~h}$ in hypertonic (Hyp) medium containing calyculin (0-30 nM), an inhibitor of protein serine/threonine phosphatases, stimulated transport activity of BGT1 but not amino acid transport system ATA2 or taurine transport (TauT). Data are mean \pm SD of 3-7 experiments. * Significantly different $(P<0.05)$ from isotonic (Iso) controls.

were compared by Student's $t$-test or by analysis of variance and Tukey's test for multiple comparisons. All images are representative of several cells on each coverglass.

\section{Results and Discussion}

When phosphorylation reactions were enhanced in MDCK cells by use of inhibitors of serine and threonine phosphatases PP1 and PP2A [17], this was a dose-dependent stimulation of BGT1 transport suggesting that phosphorylation steps were required for upregulation of BGT1 transport during hypertonic stress. For example, calyculin applied when MDCK cells were switched to hypertonic medium (500 mOsm) for $3 \mathrm{~h}$ caused an increase in $\mathrm{Na}^{+} / \mathrm{GABA}$ cotransport that was significant at $3 \mathrm{nM}$ calyculin (Figure 1). Note that there was no significant upregulation in the untreated controls $(0 \mathrm{nM})$, because a $3 \mathrm{~h}$ exposure to hypertonicity is not sufficient to upregulate BGT1 transport activity. Although plasma membrane insertion of some BGT1 proteins can be detected by $2 \mathrm{~h}$ hypertonicity [19], a period of more than $10-12 \mathrm{~h}$ is required in order to measure significant upregulation of whole cell transport activity [30]. Notably, there was no effect of calyculin on the transport activity of either ATA2 and TauT which, like BGT1, are located in the basolateral plasma membrane of MDCK cells.

Use of okadaic acid, an alternative phosphatase inhibitor in MDCK cells [31], produced similar findings. Within $5 \mathrm{~h}$ after switching MDCK cells to hypertonic medium containing okadaic acid, there was significant stimulation of $\mathrm{Na}^{+} / \mathrm{GABA}$ cotransport in response to $0.3 \mu \mathrm{M}$ okadaic acid (Figure 2). In contrast, the amino acid transport system ATA2 remained unaltered.

A complementary approach was to use inhibitors of protein kinase $\mathrm{C}(\mathrm{PKC})$, as well as long-term downregulation by phorbol ester, to determine if direct blockade of phosphorylation by this enzyme would inhibit hypertonic activation of BGT1 transport activity. The inhibitors tested were Go6976 which targets the classical protein kinases $C \alpha$ and $C \beta$ [32] and staurosporine which targets a broad spectrum of protein kinases in MDCK cells [33]. In addition, overnight (16 hr) incubation with phorbol 12-myristate 13-acetate (PMA) also 


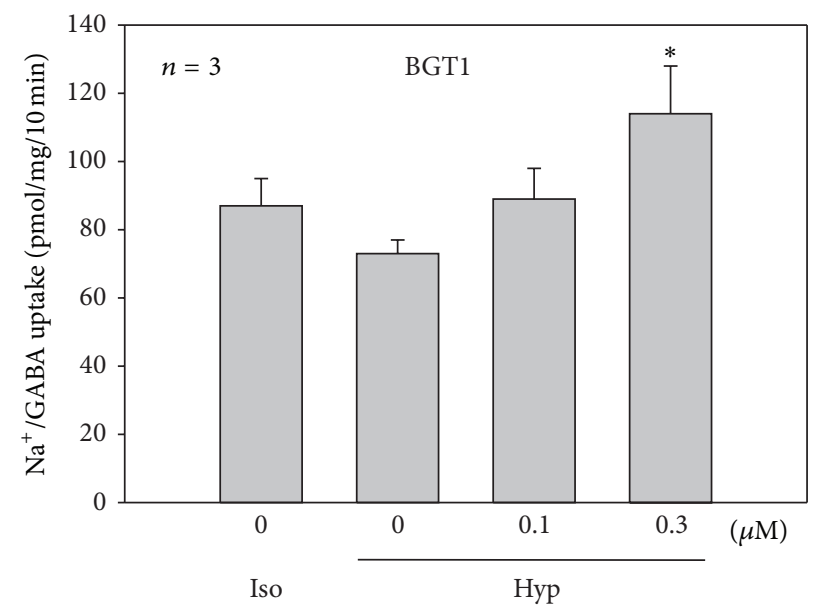

(a)

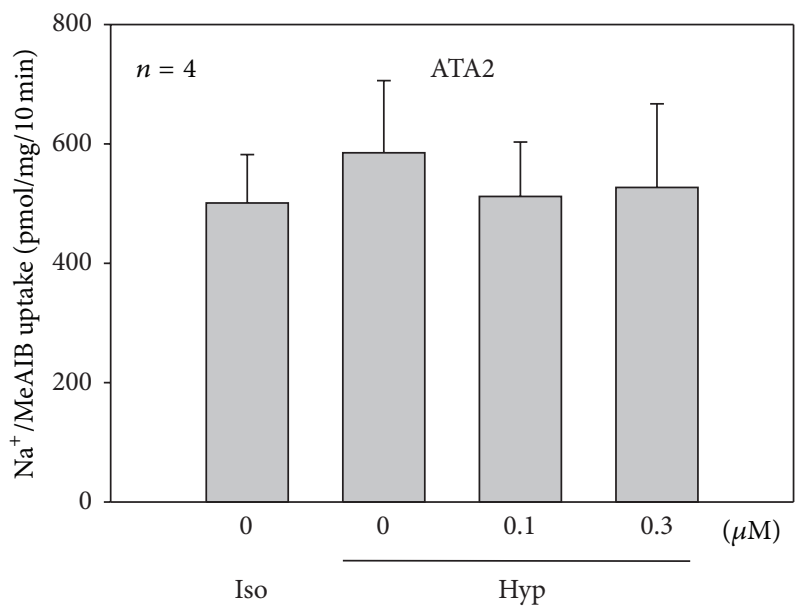

(b)

FIGURE 2: Inhibition of protein serine/threonine phosphatases by $5 \mathrm{~h}$ incubation in hypertonic medium containing okadaic acid ( $0-0.3 \mu \mathrm{M})$ stimulated transport activity of BGT1 but not amino acid transport system ATA2. Data are mean \pm SD of 3-4 experiments. * Significantly different $(P<0.05)$ compared to isotonic controls.
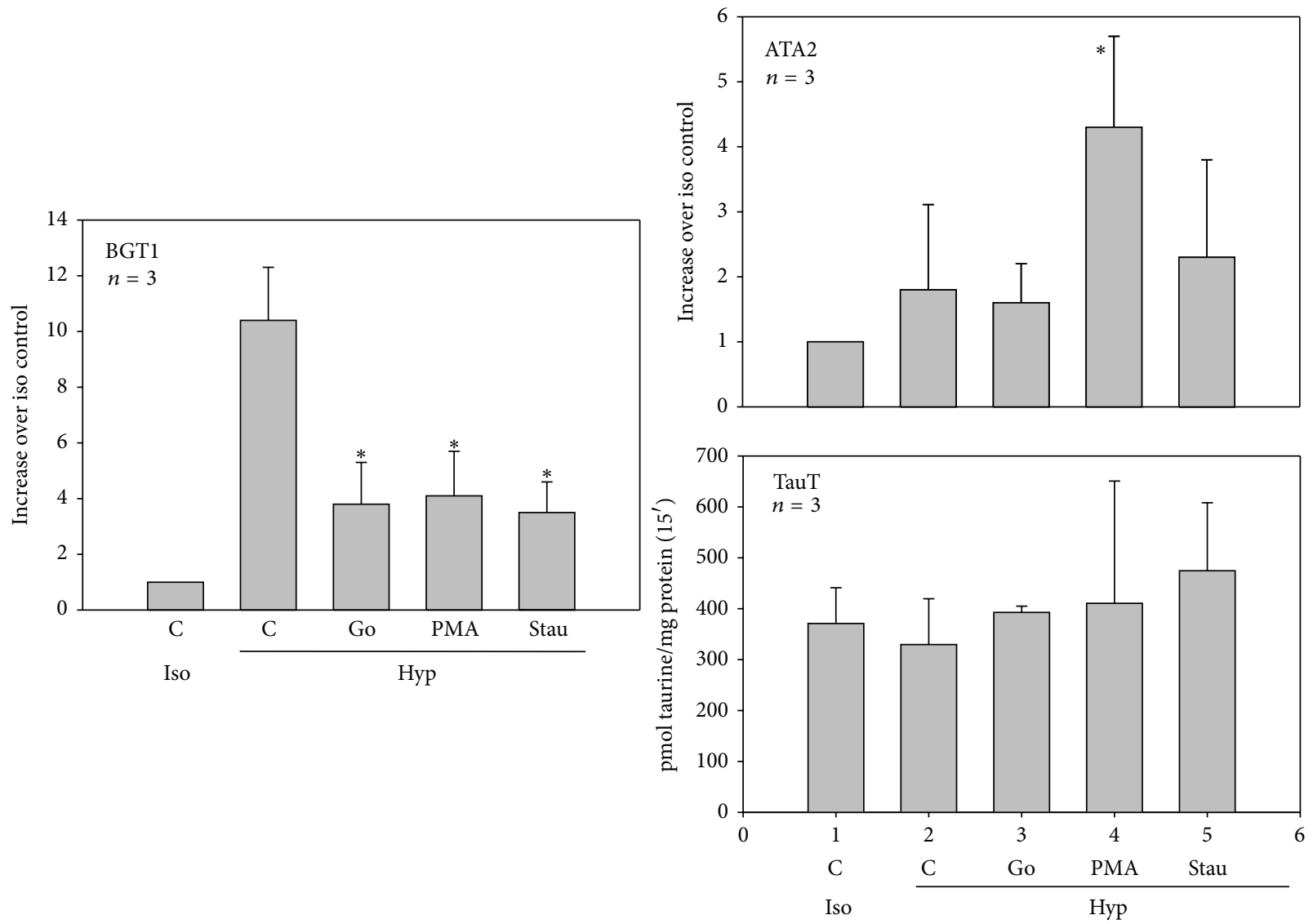

FIGURE 3: MDCK cells were incubated overnight ( $16 \mathrm{~h})$ in isotonic or hypertonic medium and in the absence (controls C) or presence of conditions that inhibit or downregulate protein kinase $\mathrm{C}$ activity. The latter impaired hypertonic upregulation of BGT1 transport but not ATA2 or TauT. * Significantly different $(P<0.02, n=3)$ compared to hypertonic controls. Final concentrations were $10 \mu \mathrm{M}$ for Go6976 (Go), $50 \mathrm{nM}$ for phorbol 12-myristate 13-acetate (PMA), and $0.3 \mu \mathrm{M}$ for staurosporine (Stau). 


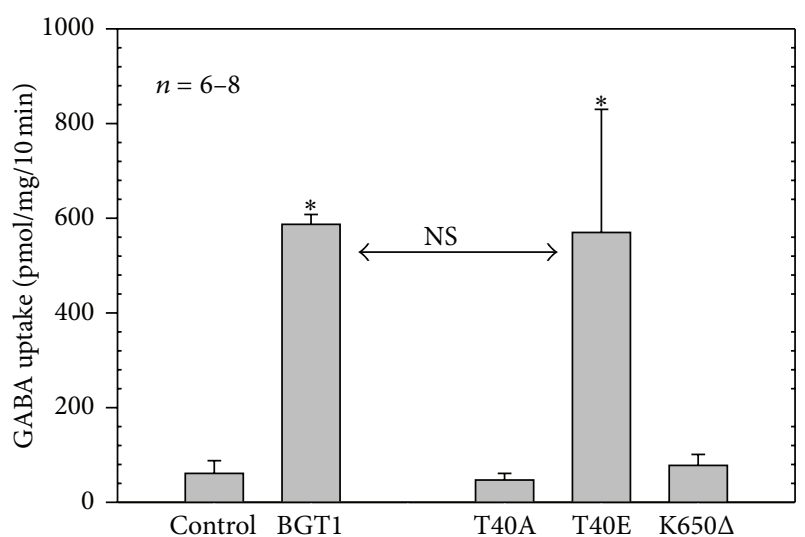

FIgURE 4: $\mathrm{Na}^{+}$-dependent GABA transport by HEK 293 cells after transfection with EGFP-tagged BGT1 or mutants followed by hypertonic stress $(450 \mathrm{mOsm})$ for $6 \mathrm{~h}$. Controls were transfected with empty EGFP vector. Data are mean \pm SD of 6-8 separate experiments. ${ }^{*}$ Significantly different $(P<0.02)$ compared to controls.

was used to downregulate PKC activity in MDCK cells [34]. As before, these drugs were applied at the same time as cells were switched to hypertonic medium and BGT1 transport activity was measured $16 \mathrm{~h}$ later. As expected after prolonged hypertonicity, BGT1 transport activity was increased 10-fold in hypertonic controls, but the upregulation was significantly reduced in the presence of each of the tested drugs (Figure 3). In contrast, there was no effect on the ATA2 and TauT transport systems, indicating specific action on BGT1.

These initial data do not yield any new information on the possible effect of hypertonic stress on protein phosphatase activity. Overall they provide indirect support for a potential role for phosphorylation in the upregulation of BGT1 transport during hypertonic stress. To determine if direct phosphorylation of BGT1 was required, we tested the behavior of four different EGFP-tagged mutants in which potential PKC phosphorylation sites in BGT1 were blocked by substitution with alanine. The mutants were expressed in MDCK cells, subjected to hypertonic stress (500 mOsm) overnight ( $16 \mathrm{~h}$ ), followed by fixation in paraformaldehyde and processing for confocal microscopy. Three of the mutants, namely, T235A, S418A, and S564A were localized primarily in the plasma membrane identical to the distribution of native EGFP-BGT1. In contrast, the fourth mutant, T40A, remained intracellular. The same was true for the truncated mutant K560 $\Delta$ which lacks plasma membrane targeting motifs. Substitution of T40 with glutamate (T40E) or aspartate (T40D) to mimic phosphorylation at this site fully restored the normal localization at the plasma membrane (data not shown).

The absence of T40A from the plasma membrane was confirmed by whole cell transport studies following transfection of the EGFP-tagged mutants in HEK293 cells that lack endogenous BGT1 [19]. Transport activity was determined after $6 \mathrm{~h}$ exposure to hypertonic medium ( $450 \mathrm{mOsm})$. Compared to controls transfected with empty vector, $\mathrm{Na}^{+} / \mathrm{GABA}$ cotransport was increased $15-20$-fold in cells transfected with native BGT1. However, in marked contrast, transport activity in cells expressing T40A was not different from the controls (Figure 4), confirming that T40A was not located at the plasma membrane. As expected, cells expressing the truncated mutant $\mathrm{K} 560 \Delta$ also demonstrated a low level of $\mathrm{Na}^{+} /$GABA cotransport that was not different from the controls and T40A. In contrast, $\mathrm{Na}^{+} / \mathrm{GABA}$ cotransport in cells expressing T40E was not significantly different from cells expressing native BGT1 (Figure 4), confirming a normal plasma membrane location. T40D could not be tested because of a low expression level in HEK293 cells. Taken together these data in two different cell lines suggest that phosphorylation at T40 may be required for successful trafficking of BGT1 protein to the plasma membrane.

Finally, the intracellular location of T40A was examined in light of the possibility that it was simply trapped in the endoplasmic reticulum, because the alanine substitution caused misfolding of the expressed protein [35]. This appears unlikely since substitution of T40 with glutamate (T40E) or aspartate (T40D) did not impair normal trafficking to the plasma membrane. Live-cell epifluorescence imaging was used after cotransfection of MDCK cells with EGFPtagged BGT1 or mutants and mCherry-tagged markers for endoplasmic reticulum, endosomes, or Golgi. The exposure to hypertonic stress ( $500 \mathrm{mOsm}$ ) was limited to $4 \mathrm{~h}$, because we showed previously in live MDCK cells [19] that this time interval allows for easily observable localization of EGFPBGT1 in both cytoplasm and plasma membrane. This was confirmed in the present study. While some EGFP-BGT1 remained in the cytoplasm, there was significant localization at the plasma membrane (green fluorescence, Figure 5(a)) and there was no colocalization with the red fluorescence of calnexin (endoplasmic reticulum), RhoB-GTPase (endosomes), or SiT (Golgi). As expected, the K560 $\Delta$ mutant was not located in the plasma membrane, but its distribution almost completely overlapped calnexin, as indicated by the yellow color generated by the merging of green and red fluorescence (Figure 5(b)). There was no colocalization with RhoB-GTPase or SiT confirming that K560 $\Delta$ remained in the endoplasmic reticulum due to loss of plasma membrane trafficking motifs and presumably was destined for degradation in the cytosol [35]. The T40A mutant also showed no plasma membrane localization and no colocalization with calnexin. However, there was significant colocalization with RhoBGTPase and some colocalization with SiT (yellow color, Figure $5(\mathrm{c})$ ). This strongly suggests that $\mathrm{T} 40 \mathrm{~A}$ is properly folded and assembled and exits the endoplasmic reticulum [35]. It is trafficked to the Golgi and endosomal compartments but cannot be inserted into (or retained in) the plasma membrane.

The intracellular location of T40A was examined also by immunohistochemistry of fixed MDCK cells labeled with an antibody to furin, an endoprotease in the trans-Golgi network. Prior to fixation, the cells were transfected with EGFP-tagged BGT1 or T40A overnight and subjected to hypertonic stress ( $500 \mathrm{mOsm}$ ) for $5 \mathrm{~h}$. Confocal microscopy revealed colocalization of EGFP-tagged T40A with furin which was located using a secondary antibody tagged with Cy5 (Figures 6(b) and 6(c)). As in Figure 5, there was significant localization of native EGFP-BGT1 in the plasma 

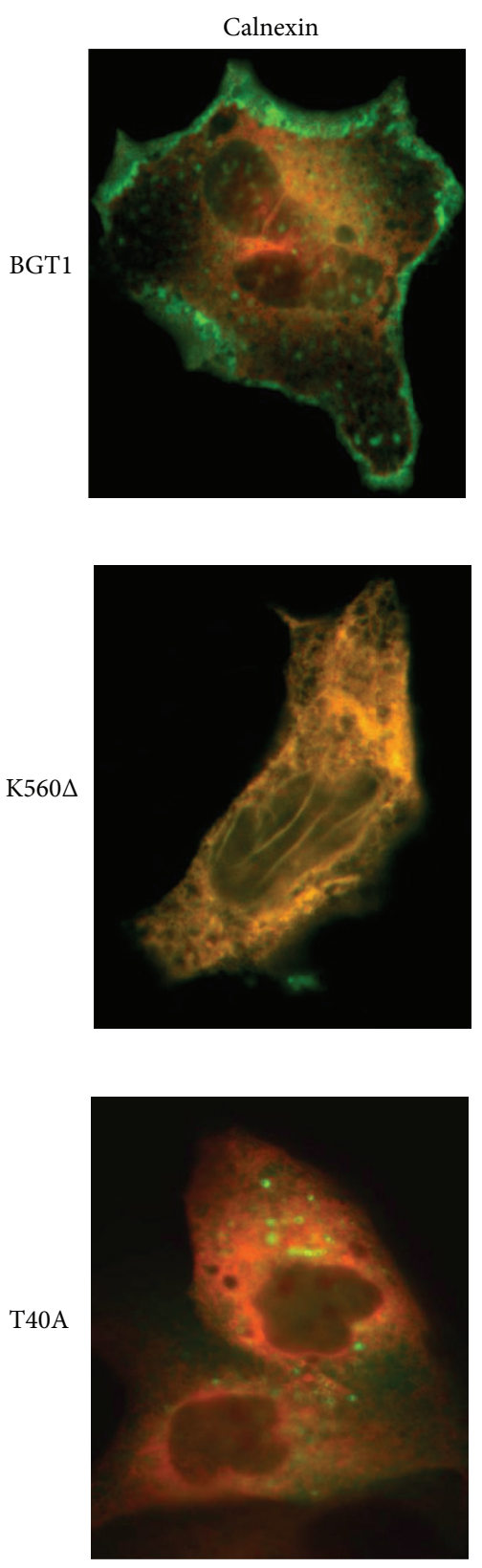

RhoB-GTPase

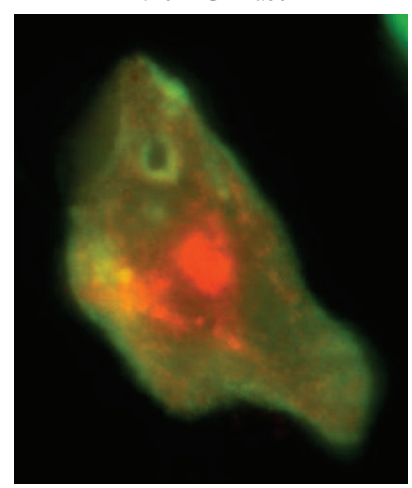

(a)

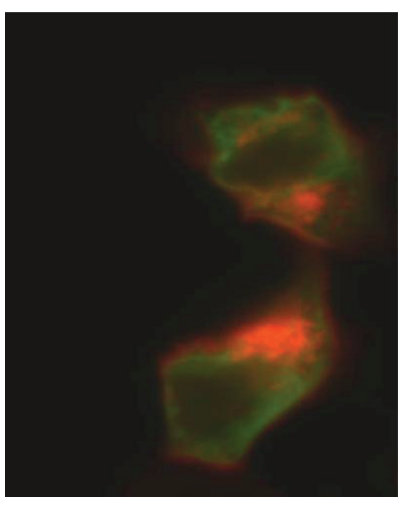

(b)

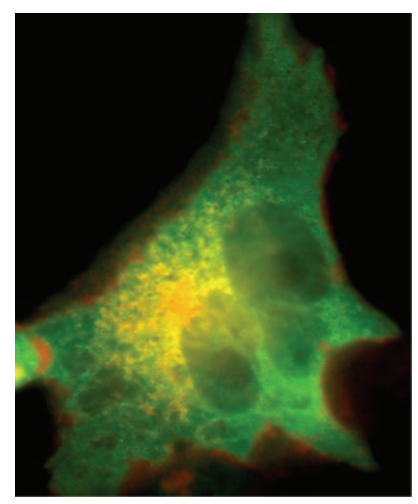

(c)
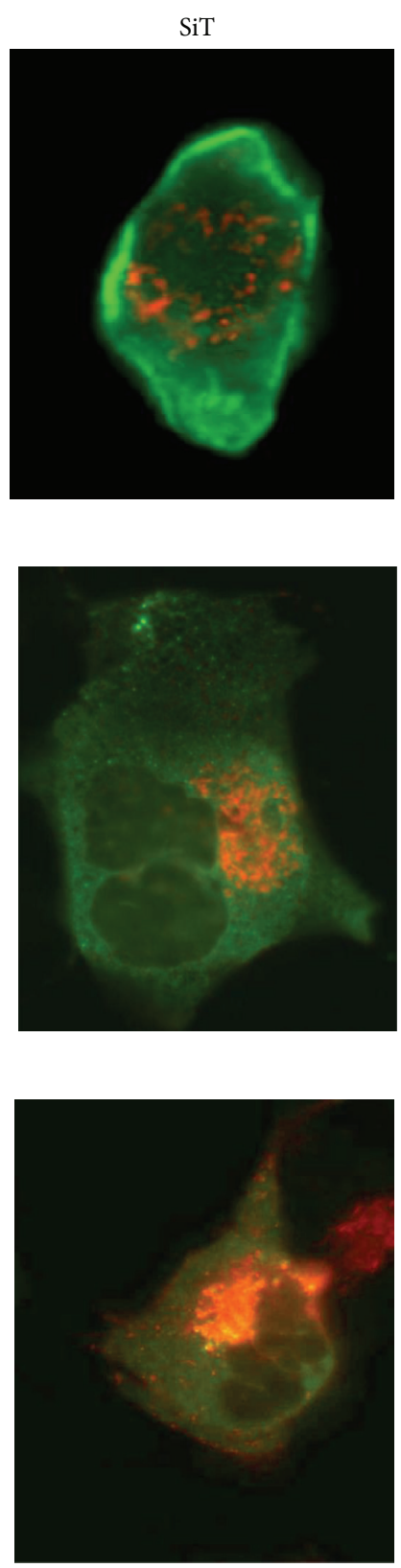

FIGURE 5: Epifluorescent images of live MDCK cells expressing EGFP-tagged BGT1 (a), K560 $\Delta$ (b), or T40A (c). Cells were cotransfected with mCherry-tagged markers (red fluorescence) for endoplasmic reticulum (calnexin), endosomes (RhoB-GTPase), and Golgi (sialyltransferase, SiT). Images were captured after hypertonic stress for $4 \mathrm{~h}$.

membrane (Figure 6(a)) even after this relatively short period of hypertonic stress.

It might be argued that the localization of T40A protein with the endosomal compartment (Figure 5(c)) reflects rapid removal from the plasma membrane, because phosphorylation at T40 is required for stable plasma membrane insertion and attachment. However, it was reported previously that endocytic removal of BGT1 from the plasma membrane required PKC-mediated phosphorylation at T612 [23]. Consequently, our finding that inhibitors of PKC impaired the normal upregulation of BGT1 transport activity in whole cells during overnight hypertonic stress (Figure 3) does not support this mechanism. Instead it supports the notion that normal trafficking of BGT1 to the plasma membrane requires normal PKC activity and phosphorylation at T40, in addition to C-terminal trafficking motifs. Pertinent additional data are the observations that hypertonic stress of hepatocytes activates isoforms of $\mathrm{PKC}$ which in turn can activate cation channels [36, 37]. This is the first report that a residue near the $\mathrm{N}$ terminus may play an important role in intracellular 


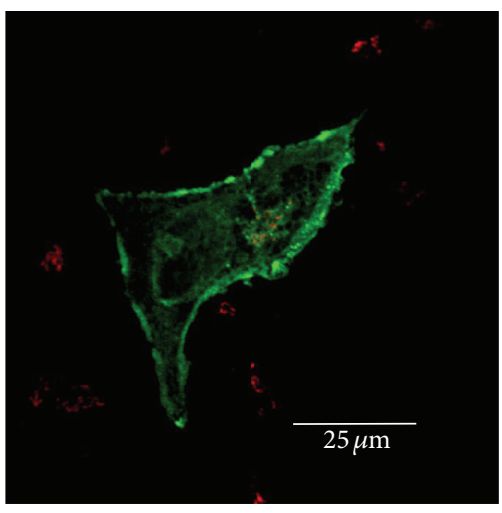

(a)

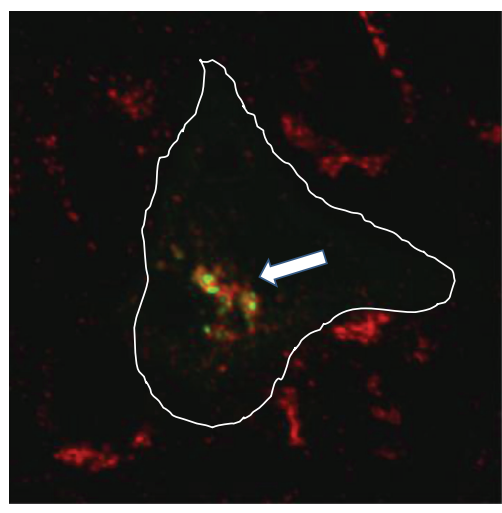

(b)

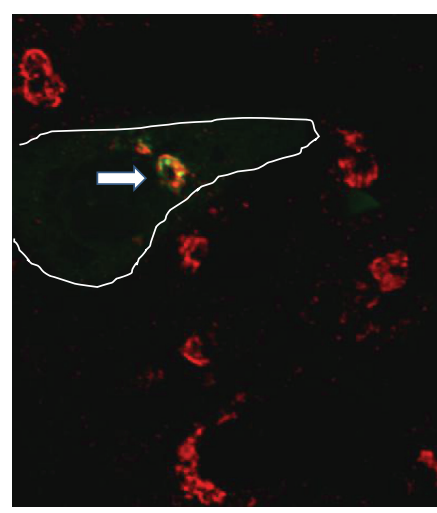

(c)

FIGURE 6: Confocal images of EGFP-tagged native BGT1 or T40A mutant expressed in MDCK cells following hypertonic stress for $5 \mathrm{~h}$. At the end of this period, the cells were fixed and immunostained for furin (red fluorescence), a marker for the trans-Golgi network. BGT1 showed significant localization in the plasma membrane (panel (a)). In contrast, T40A remained intracellular and colocalized with furin (arrows, panels (b) and (c)). Cell outline is shown in white.

trafficking of BGT1 protein. It remains to be determined if BGT1 is phosphorylated at T40 during hypertonic stress and if this is mediated by PKC. This will be addressed in future studies.

In summary, the control of BGT1 transport activity in kidney cells occurs at several levels starting with regulation of gene expression of the TonEBP transcription factor [38] and culminating with posttranslational regulation of abundance of BGT1 protein in the plasma membrane by insertion and retrieval [19, 23, 39]. Apart from residues 565-572 (28) and T612 [23], the function of specific regions within BGT1 has barely been explored, and an additional layer of complexity may emerge as the protein structure-function relationships are better understood. The BetP protein in certain bacteria is an example of such complexity. It is a $\mathrm{Na}^{+}$-coupled betaine transporter which, in addition to its transport function, is capable of both osmosensing and osmoregulation [40].

This is the first report suggesting that posttranslational modification may be involved in BGT1 regulation. It is possible that similar modifications also upregulate the transport proteins responsible for accumulation of other osmolytes, such as myo-inositol (SMIT) and taurine (TauT), but there have been no reports so far. Unlike BGT1, the system A amino acid transporter (ATA2) is upregulated much more rapidly by hypertonic stress, so that amino acids can be accumulated as an interim source of osmolytes [41]. Similar to BGT1, the density of ATA2 functioning on the cell surface is reduced by endocytotic sequestration and proteasomal degradation $[39,42]$.

\section{Acknowledgments}

The authors thank Dr. Michael Davidson (Florida State University, Tallahassee, FL, USA) for supplying mCherry-tagged organelle markers. Drs. Gerhard Burckhardt (University of Gottingen, Germany), Richard Day, and Simon Rhodes (Indiana University School of Medicine, Indianapolis, IN, USA) generously provided advice and assistance with molecular biology and live-cell imaging techniques. Robert Williams provided technical assistance. This work was supported by the American Heart Association Midwest Affiliate (SAK).

\section{References}

[1] M. S. Kwon, S. W. Lim, and H. M. Kwon, "Hypertonic stress in the kidney: a necessary evil," Physiology, vol. 24, no. 3, pp. 186191, 2009.

[2] L. Michea, D. R. Ferguson, E. M. Peters, P. M. Andrews, M. R. Kirby, and M. B. Burg, "Cell cycle delay and apoptosis are induced by high salt and urea in renal medullary cells," The American Journal of Physiology, vol. 278, no. 2, pp. F209-F218, 2000.

[3] H. M. Kwon, "Protein misfolding in hypertonic stress: new insights into an old idea. Focus on 'Genome-wide RNAi screen and in vivo protein aggregation reporters identify degradation of damaged protein as an essential hypertonic stress response", The American Journal of Physiology, vol. 295, no. 6, pp. C1474C1475, 2008.

[4] W. Neuhofer and F. X. Beck, "Cell survival in the hostile environment of the renal medulla," Annual Review of Physiology, vol. 67, pp. 531-555, 2005.

[5] W. Neuhofer, S. K. Woo, K. Y. Na et al., "Regulation of TonEBP transcriptional activator in MDCK cells following changes in ambient tonicity," The American Journal of Physiology, vol. 283, no. 6, pp. C1604-C1611, 2002.

[6] C. E. Irarrazabal, J. C. Liu, M. S. Burg, and J. D. Ferraris, "ATM, a DNA damage-inducible kinase, contributes to activation by high $\mathrm{NaCl}$ of the transcription factor TonEBP/OREBP," Proceedings of the National Academy of Sciences of the United States of America, vol. 101, no. 23, pp. 8809-8814, 2004.

[7] S. do Lee, S. Youn Choi, S. Woo Lim et al., “TonEBP stimulates multiple cellular pathways for adaptation to hypertonic stress: organic osmolyte-dependent and -independent pathways," The American Journal of Physiology, vol. 300, no. 3, pp. F707-F715, 2011.

[8] Y. Izumi, J. Li, C. Villers, K. Hashimoto, M. B. Burg, and J. D. Ferraris, "Mutations that reduce its specific DNA binding 
inhibit high $\mathrm{NaCl}$-induced nuclear localization of the osmoprotective transcription factor NFAT5," The American Journal of Physiology, vol. 303, no. 10, pp. C1061-C1069, 2012.

[9] D. Sheikh-Hamad, J. Di Mari, W. N. Suki, R. Safirstein, B. A. Watts, and D. Rouse, "p38 Kinase activity is essential for osmotic induction of mRNAs for HSP70 and transporter for organic solute betaine in Madin-Darby canine kidney cells," Journal of Biological Chemistry, vol. 273, no. 3, pp. 1832-1837, 1998.

[10] J. M. Capasso, C. J. Rivard, and T. Berl, "Long-term adaptation of renal cells to hypertonicity: role of MAP kinases and Na-KATPase," The American Journal of Physiology, vol. 280, no. 5, pp. F768-F776, 2001.

[11] S. C. Dahl, J. S. Handler, and H. M. Kwon, "Hypertonicityinduced phosphorylation and nuclear localization of the transcription factor TonEBP," The American Journal of Physiology, vol. 280, no. 2, pp. C248-C253, 2001.

[12] O. Nahm, W. O. O. Seung Kyoon, J. S. Handler, and H. M. Kwon, "Involvement of multiple kinase pathways in stimulation of gene transcription by hypertonicity," The American Journal of Physiology, vol. 282, no. 1, pp. C49-C58, 2002.

[13] S. A. Kempson and M. H. Montrose, "Osmotic regulation of renal betaine transport: transcription and beyond," Pflugers Archiv European Journal of Physiology, vol. 449, no. 3, pp. 227234, 2004.

[14] U. Hasler, P. Nunes, R. Bouley, H. A. J. Lu, T. Matsuzaki, and D. Brown, "Acute hypertonicity alters aquaporin-2 trafficking and induces a MAPK-dependent accumulation at the plasma membrane of renal epithelial cells," Journal of Biological Chemistry, vol. 283, no. 39, pp. 26643-26661, 2008.

[15] R. C. Williamson, A. C. N. Brown, W. J. Mawby, and A. M. Toye, "Human kidney anion exchanger 1 localisation in MDCK cells is controlled by the phosphorylation status of two critical tyrosines," Journal of Cell Science, vol. 121, no. 20, pp. 3422-3432, 2008.

[16] J. D. Klein, S. F. Martin, K. J. Kent, and J. M. Sands, "Protein kinase C- $\alpha$ mediates hypertonicity-stimulated increase in urea transporter phosphorylation in the inner medullary collecting duct," The American Journal of Physiology, vol. 302, no. 9, pp. F1098-F1103, 2012.

[17] J. A. Payne, C. Ferrell, and C. Y. Chung, "Endogenous and exogenous $\mathrm{Na}-\mathrm{K}-\mathrm{Cl}$ cotransporter expression in a low $\mathrm{K}$ resistant mutant MDCK cell line," The American Journal of Physiology, vol. 280, no. 6, pp. C1607-C1615, 2001.

[18] I. Matskevitch, C. A. Wagner, C. Stegen et al., "Functional characterization of the betaine $/ \gamma /$-aminobutyric acid transporter BGT-1 expressed in Xenopus oocytes," Journal of Biological Chemistry, vol. 274, no. 24, pp. 16709-16716, 1999.

[19] S. A. Kempson, V. Parikh, L. Xi, S. Chu, and M. H. Montrose, "Subcellular redistribution of the renal betaine transporter during hypertonic stress," The American Journal of Physiology, vol. 285, no. 5, pp. C1091-C1100, 2003.

[20] S. A. Kempson, J. M. Edwards, A. Osborn, and M. Sturek, "Acute inhibition of the betaine transporter by ATP and adenosine in renal MDCK cells," The American Journal of Physiology, vol. 295, no. 1, pp. F108-F117, 2008.

[21] A. Yamauchi, S. Uchida, H. M. Kwon et al., "Cloning of a $\mathrm{Na}^{+}-$ and $\mathrm{Cl}^{-}$-dependent betaine transporter that is regulated by hypertonicity," Journal of Biological Chemistry, vol. 267, no. 1, pp. 649-652, 1992.

[22] M. E. Ruiz-Tachiquín, E. Sánchez-Lemus, L. E. Soria-Jasso, J. A. Arias-Montaño, and A. Ortega, " $\gamma$-aminobutyric acid transporter (BGT-1) expressed in human astrocytoma U373 Mg cells: pharmacological and molecular characterization and phorbol ester-induced inhibition," Journal of Neuroscience Research, vol. 69, no. 1, pp. 125-132, 2002.

[23] S. Massari, C. Vanoni, R. Longhi, P. Rosa, and G. Pietrini, "Protein kinase C-mediated phosphorylation of the BGT1 epithelial $\gamma$-aminobutyric acid transporter regulates its association with LIN7 PDZ proteins: a post-translational mechanism regulating transporter surface density," Journal of Biological Chemistry, vol. 280, no. 8, pp. 7388-7397, 2005.

[24] S. Uchida, T. Nakanishi, H. M. Kwon, A. S. Preston, and J. S. Handler, "Taurine behaves as an osmolyte in Madin-Darby canine kidney cells: protection by polarized, regulated transport of taurine," Journal of Clinical Investigation, vol. 88, no. 2, pp. 656-662, 1991.

[25] X. Han, A. B. Patters, D. P. Jones, I. Zelikovic, and R. W. Chesney, "The taurine transporter: mechanisms of regulation," Acta Physiologica, vol. 187, no. 1-2, pp. 61-73, 2006.

[26] S. A. Kempson, J. A. Beck, P. E. Lammers, J. S. Gens, and M. H. Montrose, "Membrane insertion of betaine/GABA transporter during hypertonic stress correlates with nuclear accumulation of TonEBP," Biochimica et Biophysica Acta, vol. 1712, no. 1, pp. 71-80, 2005.

[27] B. S. Luciano, S. Hsu, P. L. Channavajhala, L. L. Lin, and J. W. Cuozzo, "Phosphorylation of threonine 290 in the Activation Loop of Tp12/Cot is necessary but not sufficient for kinase activity," Journal of Biological Chemistry, vol. 279, no. 50, pp. 52117-52123, 2004.

[28] C. Perego, A. Bulbarelli, R. Longhi et al., "Sorting of two polytopic proteins, the $\gamma$-aminobutyric acid and betaine transporters, in polarized epithelial cells," Journal of Biological Chemistry, vol. 272, no. 10, pp. 6584-6592, 1997.

[29] M. Teuchert, S. Berghöfer, H. D. Klenk, and W. Garten, "Recycling of furin from the plasma membrane. Functional importance of the cytoplasmic tail sorting signals and interaction with the AP-2 adaptor medium chain subunit," Journal of Biological Chemistry, vol. 274, no. 51, pp. 36781-36789, 1999.

[30] A. Yamauchi, H. M. Kwon, S. Uchida, A. S. Preston, and J. S. Handler, "Myo-inositol and betaine transporters regulated by tonicity are basolateral in MDCK cells," The American Journal of Physiology, vol. 261, no. 1, pp. F197-F202, 1991.

[31] V. Nunbhakdi-Craig, T. Machleidt, E. Ogris, D. Bellotto, C. L. White III, and E. Sontag, "Protein phosphatase 2A associates with and regulates atypical PKC and the epithelial tight junction complex," Journal of Cell Biology, vol. 158, no. 5, pp. 967-978, 2002.

[32] J. Koivunen, V. Aaltonen, S. Koskela, P. Lehenkar, M. Laato, and J. Peltonen, "Protein kinase $\mathrm{C} \alpha / \beta$ inhibitor Go6976 promotes formation of cell junctions and inhibits invasion of urinary bladder carcinoma cells," Cancer Research, vol. 64, no. 16, pp. 5693-5701, 2004.

[33] C. B. Brewer and V. G. Roth, "Polarized exocytosis in MDCK cells is regulated by phosphorylation," Journal of Cell Science, vol. 108, no. 2, pp. 789-796, 1995.

[34] C. R. J. Kennedy, R. L. Hébert, M. T. Do, and P. R. Proulx, "Bradykinin-stimulated arachidonic acid release from MDCK cells is not protein kinase C dependent," The American Journal of Physiology, vol. 273, no. 5, pp. C1605-C1612, 1997.

[35] I. Braakman and N. J. Bulleid, "Protein folding and modification in the mammalian endoplasmic reticulum," Annual Review of Biochemistry, vol. 80, pp. 71-99, 2011.

[36] K. Bierhals, A. C. Sondersorg, C. T. Lin, C. Rosenbaum, H. Waldmann, and F. Wehner, "The $\varepsilon$-isoform of PKC mediates the 
hypertonic activation of cation channels in confluent monolayers of rat hepatocytes," Cellular Physiology and Biochemistry, vol. 20, no. 5, pp. 397-404, 2007.

[37] H. Heinzinger, F. van den Boom, H. Tinel, and F. Wehner, "In rat hepatocytes, the hypertonic activation of $\mathrm{Na}^{+}$conductance and $\mathrm{Na}^{+}-\mathrm{K}^{+}-2 \mathrm{Cl}^{-}$symport-But not $\mathrm{Na}^{+}-\mathrm{H}^{+}$antiport-Is mediated by protein kinase C," Journal of Physiology, vol. 536, no. 3, pp. 703-715, 2001.

[38] M. B. Burg and J. D. Ferraris, "Intracellular organic osmolytes: function and regulation," Journal of Biological Chemistry, vol. 283, no. 12, pp. 7309-7313, 2008.

[39] S. A. Kempson, J. M. Edwards, and M. Sturek, "Inhibition of the renal betaine transporter by calcium ions," The American Journal of Physiology, vol. 291, no. 2, pp. F305-F313, 2006.

[40] V. Ott, J. Koch, K. Späte, S. Morbach, and R. Krämer, "Regulatory properties and interaction of the $\mathrm{C}$ - and $\mathrm{N}$-terminal domains of BetP, an osmoregulated betaine transporter from Corynebacterium glutamicun," Biochemistry, vol. 47, no. 46, pp. 12208-12218, 2008.

[41] S. A. Kempson, "Differential activation of system A and betaine/GABA transport in MDCK cell membranes by hypertonic stress," Biochimica et Biophysica Acta, vol. 1372, no. 1, pp. 117-123, 1998.

[42] T. Hatanaka, Y. Hatanaka, and M. Setou, "Regulation of amino acid transporter ATA2 by ubiquitin ligase Nedd4-2," Journal of Biological Chemistry, vol. 281, no. 47, pp. 35922-35930, 2006. 

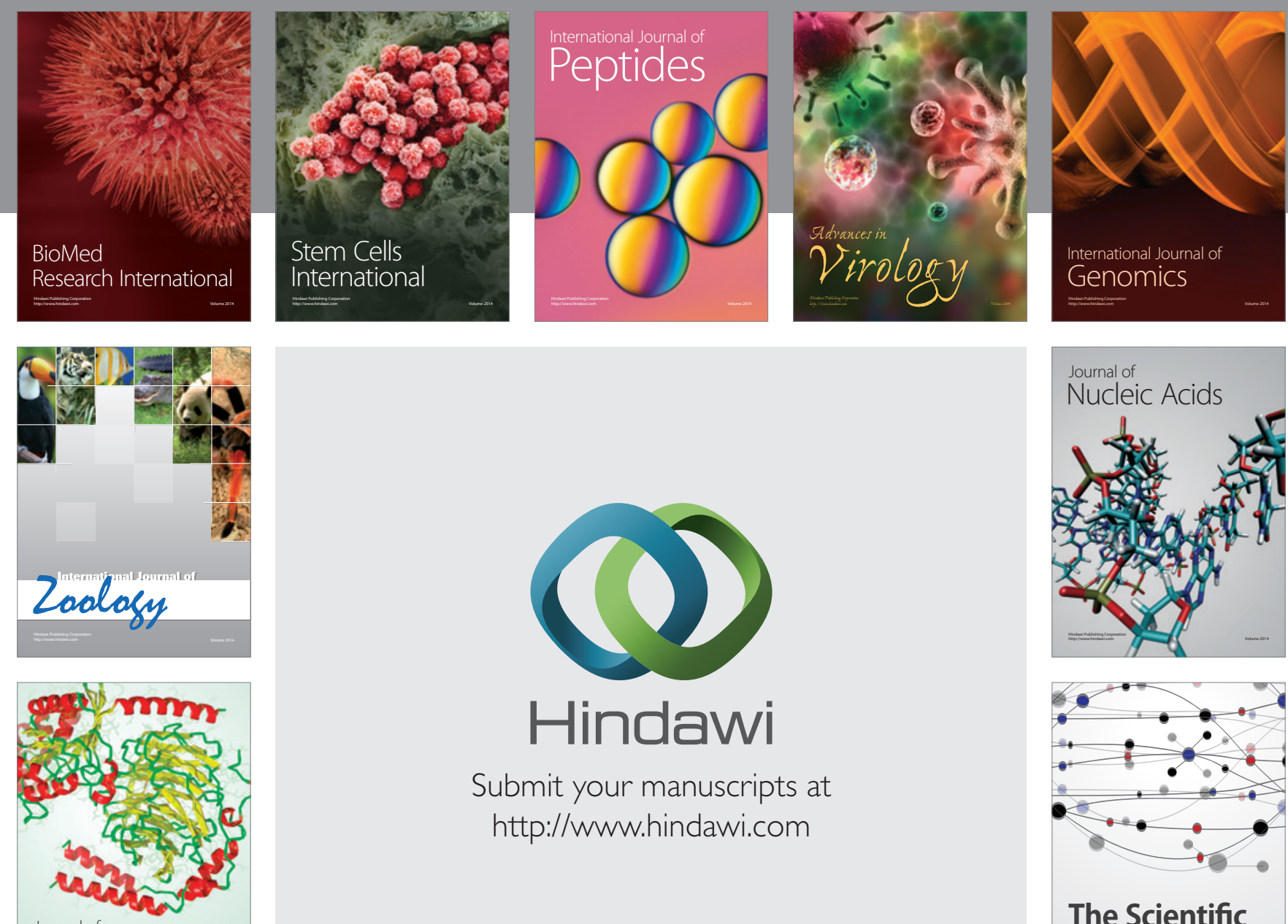

Submit your manuscripts at

http://www.hindawi.com

Journal of
Signal Transduction
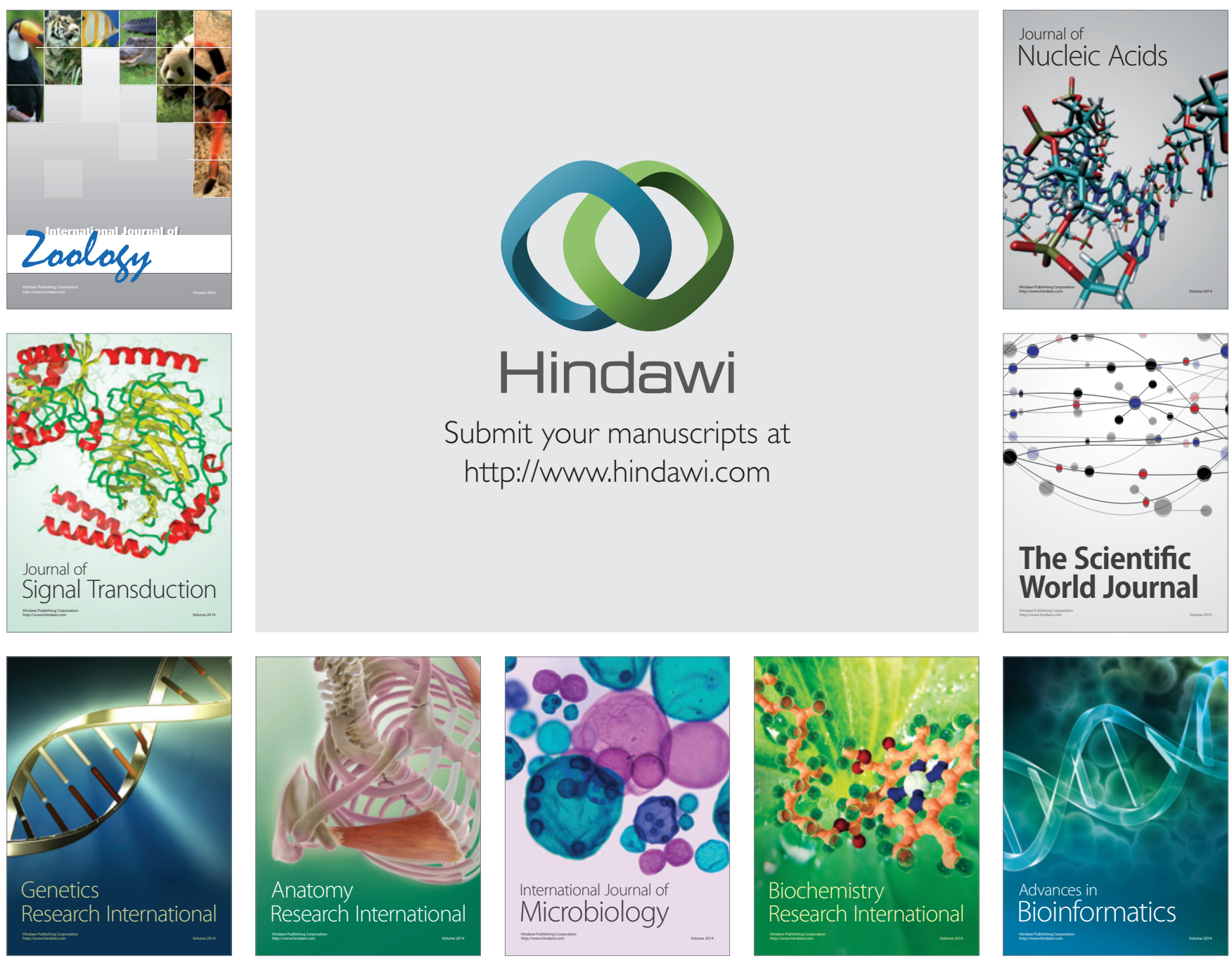

The Scientific World Journal
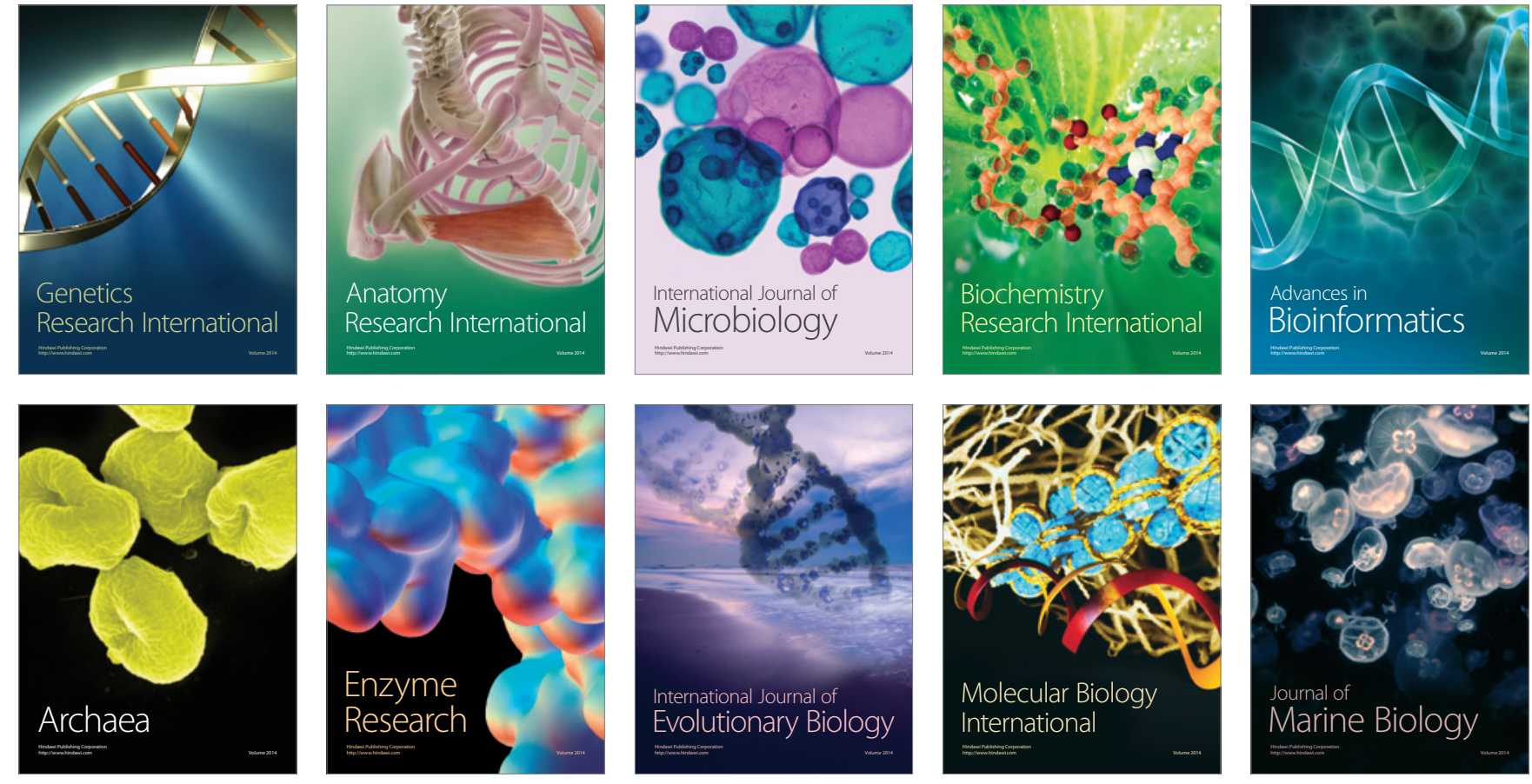